The International Journal of Banking and Finance, Volume 10 (Number 1), 2013: Pages 74-93

\title{
LEVERAGE, MATURITIES OF DEBT AND STOCK PERFORMANCE
}

Tristan Nguyen and Alexander Schüßler

WHL Graduate School of Business and Economics, Germany and HHL Leipzig Graduate School of Management, Germany

\begin{abstract}
We add to the prior literature that test the influence of total leverage on stock returns by focusing on an extended ratio, namely, 'Total Debt to (Total Capital + Long Term Debt)', $T D /(T C+L T D)$ ', the ratio henceforth. Further, and in contrast with others, we account for different maturities of debt. The link between this ratio and stock returns for periods of one to sixty months are considered for Germany, the UK and the US. We control for beta and form quintiles based on the ratio to compute mean returns. Our findings indicate a robust negative relation between the ratio and returns for Germany and the UK. In these two markets, the lowest ratioquintile performs better than the highest ratio-quintile for all the periods studied. Interestingly, the results for the United States are less clear. Due to a number of known factors, market efficiency might be higher in the US than in the other two markets.
\end{abstract}

Keywords: Stock returns, Leverage, Debt maturity, Long term debt, Short term debt JEL-Classification: G11, G12, G17

\section{Introduction}

The effect on stock returns by different accounting-based ratios has been studied via numerous empirical tests. For example, the relation between price-book ratio and stock returns is found to be negative (DeBondt and Thaler, 1987). Dividend yield, in contrast, has a positive link with stock returns (Keppler, 1991). In contrast and though tested several times, the empirical relation between leverage and stock returns is still unsettled.

In a perfect market, the relation between returns and leverage should be positive. Modigliani and Miller (1958) confirm this prediction for a restricted sample of utilities. Several other studies also analyze the link between total debt and stock returns. However, findings are inconclusive. Some studies find a positive relation (Bhandari, 1988; Dhaliwal, Heitzman and Zhen, 
2006), but others find a negative relation between leverage and stock returns. (Arditti, 1967; Korteweg, 2004; George and Hwang, 2009)

Given the mixed results, we want to shed light upon this issue. In comparison to other studies, we also distinguish between short-term and long-term debt. This is an important point because short-term debt and long-term debt have fundamentally different characters and are employed for divergent goals. That affects cost of equity. Kose (2011) studies the relation between 'short-term debt/total capital' and equity returns as well as the relation between 'long-term debt/total capital' and equity returns. He finds that stock returns increase with 'short-term debt/total capital'; however, the relation between 'long-term debt/total capital' and stock returns is negative, albeit insignificant. We use a different approach. Contrary to Kose (2011), we distinguish between different maturities of debt within one ratio, namely 'Total Debt to (Total Capital + Long Term Debt)' [TD/(TC+LTD)]. In comparison to 'total debt/total equity', 'total debt/total capital' or other conventional debt ratios, our ratio has the advantage that it treats short term debt and long term debt differently. Therefore, it accounts for the different character of debt, depending on maturity.

We run regressions for stock markets in Germany, the United Kingdom, and the United States. These countries have the largest exchanges by value of share trading in the Western World (World Federation of Exchanges, 2012). Consequently, these markets are particularly important for investors and firms. Moreover, we form quintiles depending on $T D /(T C+L T D)$ and calculate average abnormal returns for those quintiles for each market. In the process, we demonstrate what investment performance to achieve by choosing stocks based on $T D /(T C+L T D)$. The holding periods that are chosen range from one month to five years. Therefore, results are highly relevant for short-term traders as well as long-term investors. In comparison to other indicators like price-earnings ratio or price-book ratio, leverage is often ignored in the financial community. Therefore, in addition to academia, findings are also interesting for practitioners.

The structure of the paper is as follows. In the next section we give an overview of the relevant literature. Section 3 describes the methodology of the study. Section 4 shows the results and section 5 interprets the findings. Finally, in section 6 we conclude the paper and highlight major results. 


\section{Literature Review}

In an influential work, Modigliani and Miller (1958) show that in a perfect capital market, risk should increase with leverage. As a result, they expect cost of equity and stock returns to increase with leverage, which is known as proposition 2. Modigliani and Miller confirm their theory using a constricted sample of utilities. Considering corporate level taxes, they suggest that the deduction of interest expenses leads to a tax benefit for levered firms. This tax benefit raises the company value (Modigliani and Miller, 1963). Later, Miller (1977) accounts for the influence of personal taxes. According to Miller, the relative taxation of debt and equity income increases the equity risk premium from leverage.

After the work of Modigliani and Miller however, empirical studies show inconclusive results. Korteweg (2004) and Muradoglu and Sivaprasad (2012a) conduct more comprehensive tests and find that stock returns and leverage are negatively related. These results contradict one of the basic principles in traditional financial theory (Kose, 2011). Korteweg (2004) uses a time series approach and conducts a study based on capital structure changes. He supposes that investors are overly optimistic about the prospects of highly levered companies and overbuy those stocks. Muradoglu and Sivaprasad (2012a) show that investing in firms with low leverage earns abnormal returns of about 4.4 percent per annum. They find that abnormal returns are not timevarying and exist in most industries. Caskey, Hughes and Liu (2012) fragment leverage into a target component and an excess component and show that the negative relationship is driven by the excess component. They attribute their finding to investors' failure to respond immediately to news about the likeliness of distress as well as future asset growth which is included in the excess component of leverage. Muradoglu and Sivaprasad (2012b) discover that while abnormal returns decline in firm-leverage, they increase in industry-leverage, meaning that industry returns rise as the average leverage ratio within an industry rises.

In contrast to some of the prior studies, Bhandari (1988) finds a positive association between equity returns and leverage on the firm level, confirming the results of Modigliani and Miller for a more extensive sample. He controls for beta and size and uses inflation adjusted returns. In his analysis, he includes financial firms and does not account for different risk classes. Penman, Richardson and Tuna (2007) disaggregate the leverage component of the book to market ratio relating to financial risk from the leverage component relating to operational risk. They find that stock returns decrease in book leverage but increase in market leverage. Dhaliwal, Heitzman and Zhen (2006) illustrate that the effect of leverage on cost of equity is mitigated by corporate taxes. Kose (2011) accounts for different maturities of debt; he divides total debt into short-term debt 
and long-term debt. Kose finds that stocks with higher short-term debt earn higher returns and stocks with higher long-term debt earn lower returns. However, the relationship between longterm debt and stock returns is not significant.

In asset pricing models, leverage is mostly ignored due to mixed results. The conflicting evidence of the relation between leverage and equity returns motivates us to shed light on this issue. In practice, knowing the empirical relation between returns and leverage is highly relevant for investors and managers because of its importance for increasing investment performance and lowering cost of capital. We focus on the ratio $T D /(T C+L T D)$ because it takes account of different maturities of debt. Due to mixed results of former studies, we start with an open relation between $T D /(T C+L T D)$ and stock returns.

\section{Data and Methodology}

We obtain both accounting and stock market data from Datastream and use the time series from 1996 to the first quarter of 2012. This time-span ensures that we have a reasonable number of observations. We conduct our study for three countries: Germany, the United Kingdom and the United States. For each country we use 100 companies. For the United States and the United Kingdom we take the companies of the S\&P100 and the FTSE100, respectively. The S\&P100 is an index which incorporates 100 US-American large cap stocks. The FTSE100 is the most prominent stock market index in the United Kingdom for large companies. For Germany, there is no equivalent index which contains exactly 100 stocks; therefore our German sample is made up of companies from different stock market indices. We take the companies of the DAX 30, the companies of the MDAX 50 and the 20 largest companies of the SDAX to get 100 companies for Germany as well. For all countries, we exclude financial companies because they have higher leverage. Financial companies are defined as banks, insurance companies and investment firms. Moreover, we eliminate companies which alter their fiscal year end date within our research period and companies for which we do not obtain matching stock prices or fundamental ratios for the time span. After eliminating these companies, our resultant sample for the German market consists of 67 companies and 1070 observations. For the United Kingdom we have 60 companies and 944 observations and for the United States we have a resultant sample of 78 companies and 1244 observations.

Using the above data, we conduct a panel analysis. Our regressions are for holding periods of one, three, six, twelve, 36 and 60 months. The dependent variable is abnormal return (AR). We employ consecutive closing prices adjusted for dividends splits and right-issues and calculate 
returns from the first trading day of June. Hence, we ensure to have a time interval of at least five months between fiscal year end and the date from which returns are computed. Thereby, we avoid the look-ahead bias. Even though, abnormal returns refer to holding periods of up to 60 months, they are calculated on a monthly basis. We calculate abnormal returns with the market model. The market model has the advantage that it lowers the variance of abnormal returns. This raises the ability to detect the outcome (Campbell, Lo and MacKinley, 1997; Muradoglu and Sivaprasad, 2012a).

The abnormal return is defined as:

$$
A R_{i}=R_{i}-E\left(R_{i}\right)
$$

where $R_{i}$ is the return and $E\left(R_{i}\right)$ is the expected return. The subscript ${ }_{i}$ refers to the holding period in months. Stock returns are calculated as nominal returns in local currencies. Thus, returns for the United States are in US-Dollar, returns for the United Kingdom in Pound Sterling and returns for Germany is in Euro to ensure that performance is measured from the perspective of a local investor.

According to the market model, we expect the return of a share to be the return of the benchmark index. The indices are described in the prior section. The mixed German benchmark index has the following weightings: the weight of the DAX 30 is 0.3, the weight of the MDAX 50 is 0.5 and the weight of the SDAX is 0.2 .

For the holding period of $i$ months $(i=1, \ldots, 60)$, we run the following regressions for each country:

$$
A R_{i}=a+b \frac{T D}{T C+L T D}+c^{*} B E T A+\varepsilon
$$

Where,

$A R_{i}$ is the monthly abnormal stock return for a holding period of $i$ months $(i=1, \ldots, 60)$, beginning at the first trading day in June of month 0 and ending at the first trading day of month $i$.

$\frac{T D}{T C+L T D}$ stands for 'Total Debt to (Total Capital + Long Term Debt)'. Total capital is the sum of equity, short term debt and long term debt. Total debt is the sum of short term debt and long term debt.

$a$ is a constant and $b$ is the regression coefficient, $\varepsilon$ is the error term. 
To calculate the leverage ratio $T D /(T C+L T D)$, we use book values instead of market values because we want to concentrate on financial decisions rather than the influence of market fluctuations. Graham and Harvey (2001) show that executives focus on book values when determining the capital structure. Using market values is, furthermore, problematic since market values might correlate with exogenous variables (Kose, 2011). We employ $T D /(T C+L T D)$ because this is a more sophisticated leverage ratio than 'debt to equity' or 'debt to total capital' which are used in most of the cited studies. The ratio we employ treats long term debt and short term debt differently. Long term debt and short term debt fundamentally differ and are used for different purposes (Kose, 2011).

Additionally, in each regression we control for beta. Beta is calculated as the price movement of the share divided by the price movement of the corresponding index over a five year time span. Furthermore, we use a portfolio approach based on $T D /(T C+L T D)$ to realize direct investment implications of leverage. Once a year, we form five equal sized portfolios depending on $T D /(T C+L T D)$ for every holding period from one to 60 months and compute average monthly abnormal returns for each quintile. Moreover, we calculate average cumulative abnormal return for every holding period. In each of the quintiles, included stocks are equally weighted. We do this sorting for every country and use t-tests to detect differences from zero.

In our portfolio approach, we link accounting data of fiscal year t-1 to abnormal stock returns which are calculated from the first trading day of June in year t.

\section{Findings}

In this section, we show the result of our empirical study for the three markets (Germany, United Kingdom and the United States). The regression is an OLS. After regression coefficients for independent variables, corresponding standard errors are reported in parentheses. * indicates statistical significance at the $10 \%$-level, ** at the $5 \%$-level and $* * *$ at the $1 \%$-level.

\section{A. Empirical Results for Germany}

Table 1 shows the results of the cross sectional panel regression for one, three and six month holding periods, which are estimated with equation (2). The dependent variable is monthly abnormal return for respective holding periods. The model includes the independent variables $T D /(T C+L T D)$ and beta. 
Contrary to the traditional financial theory, the coefficients for $T D /(T C+L T D)$ are negative for all three holding periods, although only the one month estimate is significant. It has a value of -0.005 , implying that low $T D /(T C+L T D)$-stocks outperform high $T D /(T C+L T D)$-stocks for this time span. The coefficients for three and six months are not significantly different from zero. For the three month holding period, beta coefficient is significant. Interestingly, however, it has an unexpected sign: the coefficient is negative which is not in line with CAPM.

Table 1: Regression for Germany, Abnormal returns for 1-, 3- and 6-month periods

\begin{tabular}{|l|ll|ll|ll|}
\cline { 2 - 7 } \multicolumn{1}{c|}{} & \multicolumn{2}{c|}{ 1 month } & \multicolumn{2}{c|}{ 3 months } & \multicolumn{2}{c|}{ 6 months } \\
\hline Variable & coefficient & st.error & coefficient & st. error & coefficient & st. error \\
\hline Intercept & $1.689 * *$ & $(0.691)$ & $0.96^{* *}$ & $(0.415)$ & 0.186 & $(0.271)$ \\
TD/(TC+LTD) & $-0.005^{*}$ & $(0.003)$ & -0.002 & $(0.002)$ & -0.001 & $(0.001)$ \\
Beta & -0.981 & $(0.763)$ & $-0.969 * *$ & $(0.458)$ & -0.238 & $(0.299)$ \\
\hline$R^{2}$ & 0.006 & & 0.007 & & 0.002 & \\
F-statistics & $2.544^{*}$ & & $3.308^{* *}$ & & 0.854 & \\
Observations & 1070 & & 1070 & & 1070 & \\
\hline
\end{tabular}

Table 2: Regression for Germany, Abnormal returns for 12-, 36- and 60-month periods

\begin{tabular}{|l|ll|ll|ll|}
\cline { 2 - 7 } \multicolumn{1}{c|}{} & \multicolumn{2}{c|}{12 month } & \multicolumn{2}{c|}{36 months } & \multicolumn{2}{c|}{60 months } \\
\hline Variable & coefficient & st.error & coefficient & st. error & coefficient & st. error \\
\hline Intercept & $0.74^{* * *}$ & $(0.232)$ & 0.336 & $(0.244)$ & $0.527^{* *}$ & $(0.253)$ \\
TD/(TC+LTD) & $-0.002^{* *}$ & $(0.001)$ & -0.001 & $(0.001)$ & $-0.002^{*}$ & $(0.001)$ \\
Beta & -0.019 & $(0.256)$ & 0.028 & $(0.269)$ & -0.089 & $(0.280)$ \\
\hline $\mathrm{R}^{2}$ & 0.005 & & 0.003 & & 0.004 & \\
F-statistics & 2.192 & & 1.271 & & 1.671 & \\
Observations & 1070 & & 1070 & & 1070 & \\
\hline
\end{tabular}

Table 2 shows the regressions for holding periods of twelve, 36 and 60 months. For twelve and 60 months, both $T D /(T C+L T D)$-coefficients have a value of -0.002 . They are significant at 
the 5\%- and 10\%-level, respectively. Regression coefficients for beta are not significant for reported holding periods.

Table 3: Mean monthly abnormal returns for the German market

\begin{tabular}{|lc|c|c|r|r|r|}
\cline { 2 - 7 } \multicolumn{1}{c|}{} & AR1 & AR3 & AR6 & AR12 & AR36 & AR60 \\
\hline P1 (lowest) & 0.809 & 0.185 & 0.146 & 0.608 & 0.335 & 0.281 \\
P2 & 0.967 & 0.074 & -0.002 & 0.261 & 0.055 & 0.088 \\
P3 & 0.854 & -0.018 & -0.102 & 0.104 & -0.138 & -0.070 \\
P4 & -0.640 & 0.205 & -0.091 & -0.262 & 0.110 & 0.061 \\
P5 (highest) & -0.580 & -0.344 & -0.158 & -0.072 & -0.119 & -0.118 \\
\hline P1-P5 & 1.389 & 0.529 & 0.304 & 0.680 & 0.454 & 0.399 \\
t-value & 1.30 & 0.83 & 0.70 & $1.78 *$ & 1.00 & 0.79 \\
\hline
\end{tabular}

Table 3 shows mean abnormal returns for different portfolios. Portfolios are sorted based on $T D /(T C+L T D)$. Again, we focus on holding periods between one and 60 months and in table 3, we report monthly returns for those periods. The abnormal returns are averages across the whole time series. The reason why abnormal returns of different portfolios do not exactly add up to zero is that benchmark indices are not equally weighted. Instead, major indices like the DAX30, MDAX50, S\&P100 and FTSE100 are weighted according to market cap and/or free float of included companies. In our sample stocks are equally weighted. This is common practice and leads to the most meaningful results. However, it explains why abnormal returns do not exactly add up to zero. A second reason is that we exclude financial companies. Benchmark indices, of course, contain financial companies.

Portfolio 1 has the lowest mean TD/(TC+LTD), portfolio 5 the highest. We report spreads between P1 and P5 as well as t-values to get to know if those spreads are significantly different from zero. Results show that holding low TD/(TC+LTD)-stocks is highly profitable. The lowest quintile performs better than the highest quintile for every holding period. Considering all portfolios, those with lower leverage mostly perform better than portfolios with higher leverage, but this does not hold for all cases. For example, P4 has a better return than P3 for the three, six, 36 and 60 month holding period, although it has a higher TD/(TC+LTD) than P3. According to ttests, differences between mean abnormal returns of P1 and P5 are not random for twelve and 60 month investment periods. Spreads are significant at the $10 \%$-level. 
Table 4: Mean cumulative abnormal returns for the German market

\begin{tabular}{|lr|r|r|r|r|r|}
\cline { 2 - 7 } \multicolumn{1}{l|}{} & CAR1 & CAR3 & CAR6 & CAR12 & CAR36 & CAR60 \\
\hline P1 (lowest) & 0.81 & 0.55 & 0.88 & 7.30 & 12.07 & 16.84 \\
P2 & 0.97 & 0.22 & -0.01 & 3.13 & 1.99 & 5.30 \\
P3 & 0.85 & -0.05 & -0.61 & 1.25 & -4.95 & -4.18 \\
P4 & -0.64 & 0.61 & -0.55 & -3.15 & 3.96 & 3.64 \\
P5 (highest) & -0.58 & -1.03 & -0.95 & -0.86 & -4.28 & -7.07 \\
\hline
\end{tabular}

Table 4 shows how abnormal returns add up along the time span. For longer investment horizons, the magnitude of the outperformance of P1 is astonishing: P1 has a cumulative abnormal return of 12.1 and 16.8 percent for holding periods of 36 and 60 months. P2 still has an abnormal return of 2.0 and 5.3 percent for these time periods. In comparison, for high $T D /(T C+L T D)$-portfolios, it is the downside potential which seems to be relatively high: P5 has a negative cumulative abnormal return for all holding periods.

Figure 1: Mean cumulative abnormal returns for the German market

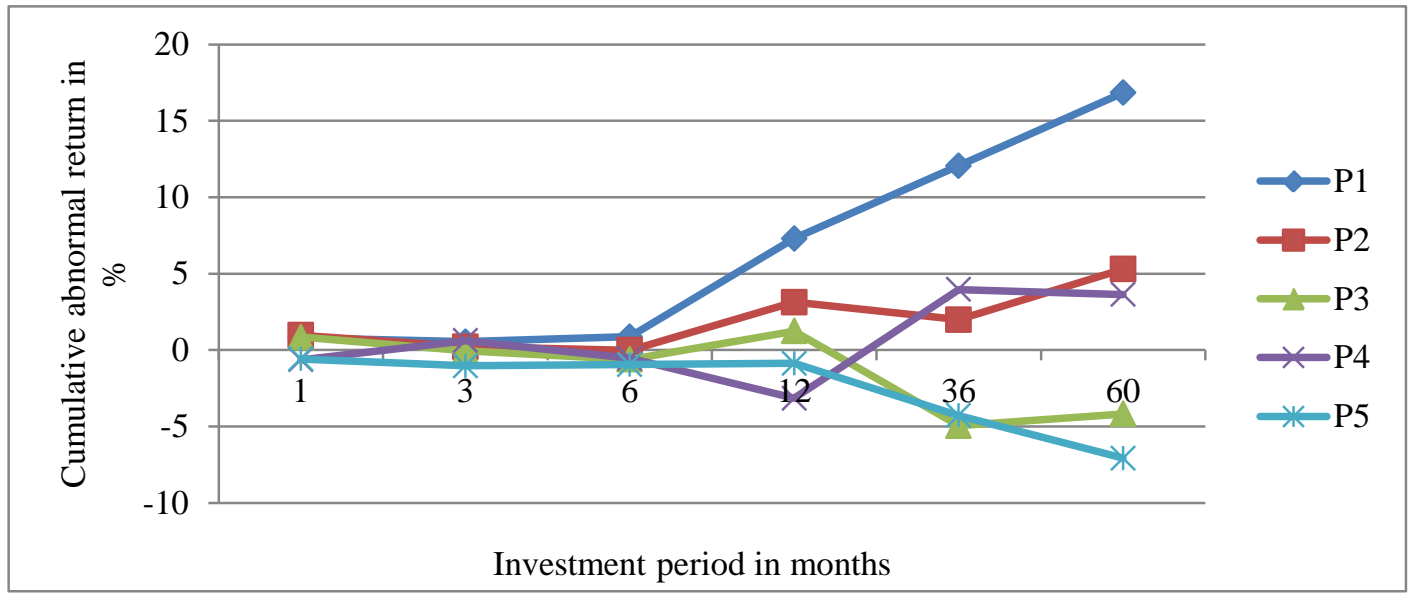

Figure 1 illustrates investment implications graphically. It shows cumulative abnormal returns along the time bar. On the x-axis, for clarity, distances between indicated values are identical. The profitability of P1 turns out to be quite persistent: P1 has the highest returns for holding periods from six to 60 months. Particularly for longer investment horizons of twelve to 60 months, it outperforms all other portfolios by a large margin. P5, the portfolio with the highest 
$T D /(T C+L T D)$, is the worst performing group for three of six holding periods. Especially for long term investors, the spread between P1 and P5 is sizable: for three years, there is a cumulative return difference of more than 16 percent; for five years, the spread between P1 and P5 even exceeds 23 percent.

\section{B. Empirical Results for the United Kingdom}

UK-regression results (Table 5) show that TD/(TC+LTD) coefficients are negative for holding periods of three, six and twelve months after controlling for beta. For three and six months, coefficients of -0.004 and -0.003 are significantly different from zero at the 5\%-level.

Table 5: Regression for the UK, Abnormal returns for 1-, 3- and 6-month periods

\begin{tabular}{|l|ll|ll|ll|}
\cline { 2 - 7 } \multicolumn{1}{c|}{} & \multicolumn{2}{c|}{ 1 month } & \multicolumn{2}{c|}{ 3 months } & \multicolumn{2}{c|}{6 months } \\
\hline Variable & coefficient & st.error & coefficient & st. error & coefficient & st. error \\
\hline Intercept & $2.847 * * *$ & $(0.714)$ & 0.433 & $(0.362)$ & 0.076 & $(0.258)$ \\
TD/(TC+LTD) & -0.006 & $(0.004)$ & $-0.004 * *$ & $(0.002)$ & $-0.003^{* *}$ & $(0.001)$ \\
Beta & $-1.992^{* * *}$ & $(0.703)$ & -0.245 & $(0.356)$ & 0.154 & $(0.253)$ \\
\hline $\mathrm{R}^{2}$ & 0.011 & & 0.006 & & 0.005 & \\
F-statistics & $5.099 * * *$ & & $2.740^{*}$ & & $2.426 *$ & \\
Observations & 944 & & 944 & & 944 & \\
\hline
\end{tabular}

Table 6: Regression for the UK, Abnormal returns for 1-, 3- and 6-month periods

\begin{tabular}{|l|ll|ll|ll|}
\cline { 2 - 7 } \multicolumn{1}{c|}{} & \multicolumn{2}{c|}{ 12 month } & \multicolumn{2}{c|}{36 months } & \multicolumn{2}{c|}{ 60 months } \\
\hline Variable & coefficient & st.error & coefficient & st. error & coefficient & st. error \\
\hline Intercept & -0.026 & $(0.237)$ & 0.103 & $(0.172)$ & $0.411^{* * *}$ & $(0.139)$ \\
TD/(TC+LTD) & -0.001 & $(0.001)$ & -0.00008 & $(0.001)$ & -0.00005 & $(0.001)$ \\
Beta & 0.115 & $(0.233)$ & 0.044 & $(0.169)$ & -0.043 & $(0.136)$ \\
\hline $\mathrm{R}^{2}$ & 0.001 & & 0.000 & & 0.000 & \\
F-statistics & 0.630 & & 0.040 & & 0.052 & \\
Observations & 944 & & 944 & & 944 & \\
\hline
\end{tabular}


Similar to the Germany sample, the beta coefficient is negative for three and six month periods. For the one month holding period, negative beta has significant predictive power for returns. After being negative for three months as well, the beta coefficient turns positive for the twelve month period, albeit it is insignificant. F-statistics show that models are significant at the $1 \%$ and $10 \%$ level; therefore results should hold for the population, too. In contrast, F-statistics for longer holding periods indicate weaker overall models. TD/(TC+LTD) coefficients are all negative but not significant. Beta coefficient as well, which is positive for twelve and 36-months, but negative for 60 -months periods, is not significantly different from zero.

Table 7: Mean monthly abnormal returns for the UK also 12-, 36- and 60-month periods

\begin{tabular}{|l|c|r|r|r|r|r|}
\cline { 2 - 7 } \multicolumn{1}{c|}{} & AR1 & AR3 & AR6 & AR12 & AR36 & AR60 \\
\hline P1 (lowest) & 0.755 & 0.650 & 0.558 & 0.360 & 0.313 & 0.057 \\
P2 & -0.180 & -0.033 & 0.070 & 0.083 & -0.091 & -0.072 \\
P3 & 0.477 & 0.010 & 0.126 & -0.116 & 0.009 & 0.083 \\
P4 & 0.988 & 0.228 & 0.065 & 0.012 & 0.096 & 0.319 \\
P5 (highest) & -0.967 & -0.801 & -0.397 & -0.226 & -0.213 & -0.294 \\
\hline P1-P5 & 1.722 & 1.450 & 0.955 & 0.586 & 0.526 & 0.352 \\
t-value & $1.89 *$ & $3.00^{* * *}$ & $2.60^{* *}$ & 1.63 & $2.05^{* *}$ & $2.10^{* *}$ \\
\hline
\end{tabular}

The UK-stocks are also sorted into TD/(TC+LTD)-quintiles. Table 7 shows that especially for large holding periods, the distribution of portfolio returns is not as clear as for the German market. For example, P2 performs relatively poorly for holding periods of 36 and 60 months (0.091\% and $-0.072 \%$ monthly abnormal return).

In contrast, $\mathrm{P} 4$ which has a higher average $T D /(T C+L T D)$, performs better for these holding periods. ( $+0.096 \%$ and $+0.319 \%$ respectively). However, on balance, like for Germany, low $T D /(T C+L T D)$-portfolios perform better than high $T D /(T C+L T D)$-portfolios. According to ttests, differences between mean abnormal returns of P5 and P1 are significant for five of six studied holding periods. This fact is impressive and raises the question if significant spreads must be attributed to investors' mistakes to overbuy high $T D /(T C+L T D)$-stocks and oversell low $T D /(T C+L T D)$-stocks.

Obviously buying low leverage stocks is successful for medium term periods: P1 has the highest return for three, six, twelve and 36 months. For the longest period, in contrast, P1 performs hardly above average with a cumulative abnormal return of 3.4\%. Two other portfolios, namely P4 and P3, are on average more successful in this time span. 
Table 8: Mean cumulative abnormal returns for the UK market for different periods

\begin{tabular}{|lr|r|r|r|r|r|}
\cline { 2 - 7 } \multicolumn{1}{c|}{} & CAR1 & CAR3 & CAR6 & CAR12 & CAR36 & CAR60 \\
\hline P1 (lowest) & 0.75 & 1.95 & 3.35 & 4.33 & 11.25 & 3.43 \\
P2 & -0.18 & -0.10 & 0.42 & 1.00 & -3.28 & -4.34 \\
P3 & 0.48 & 0.03 & 0.76 & -1.39 & 0.33 & 4.99 \\
P4 & 0.99 & 0.68 & 0.39 & 0.15 & 3.44 & 19.16 \\
P5 (highest) & -0.97 & -2.40 & -2.38 & -2.71 & -7.68 & -17.66 \\
\hline
\end{tabular}

Figure 2: Mean cumulative abnormal returns for the UK market for different periods

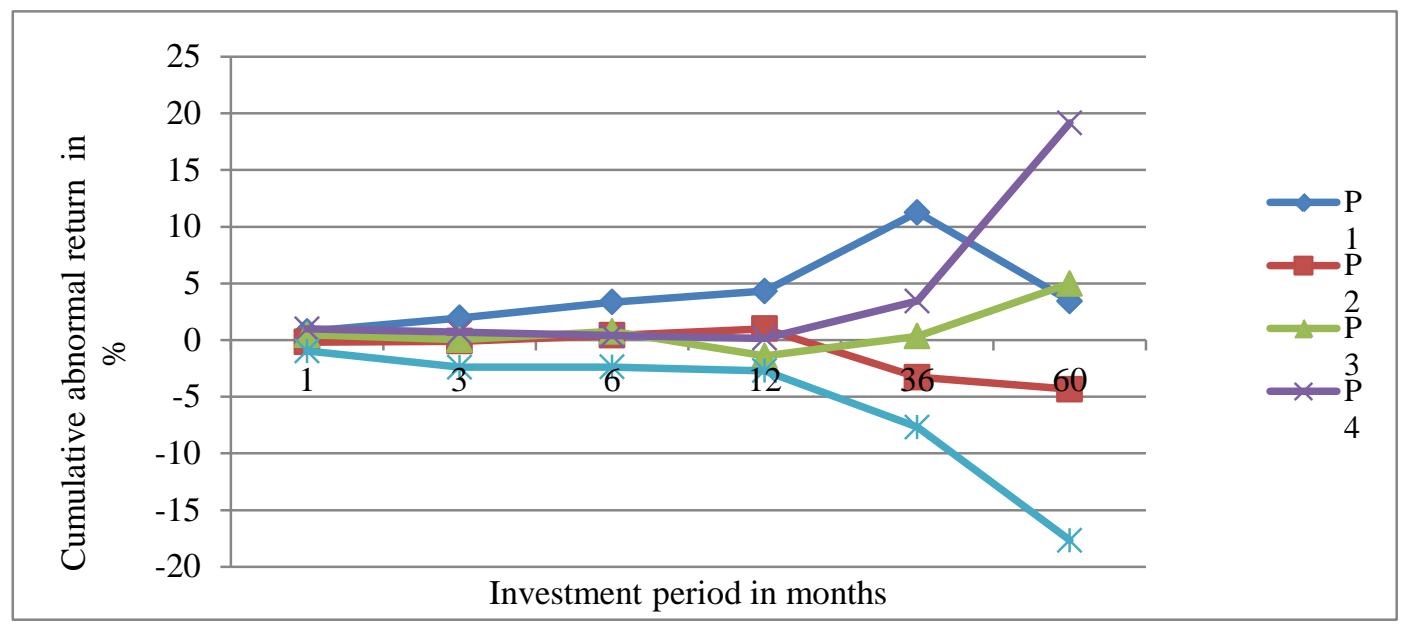

Figure 2 reports that very high leverage portfolios perform weak for all holding periods. Actually P5 has the lowest returns for every studied period. Interestingly, however, P2, a lowleverage portfolio, also performs relatively poor for longer periods of 36 and 60 months. In particular for the longest period, figure 2 demonstrates that the magnitude between the best and worst performing quintile is higher for the UK market than for the German market.

\section{Empirical Results for the United States}

As table 9 shows, the US results are mixed for short investment periods of one to six months. While we find a significant positive relation between $T D /(T C+L T D)$ and stock returns for one month, for three and six months the link is negative and the coefficients are insignificant. In line with rational models, beta coefficient is significantly positive for the one month period. But for longer horizons, it turns insignificant. 
Table 9: Regression for the USA, Abnormal returns for 1-, 3-, and 6-month periods

\begin{tabular}{|l|ll|ll|ll|}
\cline { 2 - 7 } \multicolumn{1}{c|}{} & \multicolumn{2}{c|}{ 1 month } & \multicolumn{2}{c|}{ 3 months } & \multicolumn{2}{c|}{ 6 months } \\
\hline Variable & coefficient & st.error & coefficient & st. error & coefficient & st. error \\
Intercept & $-3.357^{* * *}$ & $(0.856)$ & $0.793^{* *}$ & $(0.366)$ & -0.083 & $(0.279)$ \\
BD/(TC+LTD) & $0.027^{* *}$ & $(0.013)$ & -0.001 & $(0.006)$ & -0.003 & $(0.004)$ \\
Beta & $1.880^{* * *}$ & $(0.670)$ & -0.284 & $(0.286)$ & 0.021 & $(0.219)$ \\
\hline$R^{2}$ & 0.011 & & 0.001 & & 0.000 & \\
F-statistics & $6.729 * * *$ & & 0.511 & & 0.287 & \\
\hline
\end{tabular}

Considering longer periods (see Table 10), the findings for the United States are also ambiguous. Even though the $T D /(T C+L T D)$ coefficient for 36 months of -0.007 is significant at the 5\%-level, other $T D /(T C+L T D)$ coefficients are not significant. In summary in comparison to the German and the UK markets, regression results for the US market are inconclusive and do not show a clear relation.

Table 10: Regression for the USA, Abnormal returns for 12-, 36- and 60-month periods

\begin{tabular}{|l|ll|ll|ll|}
\cline { 2 - 7 } \multicolumn{1}{c|}{} & \multicolumn{2}{c|}{ 12 month } & \multicolumn{2}{c|}{ 36 months } & \multicolumn{2}{c|}{ 60 months } \\
\hline Variable & -0.014 & $(0.279)$ & $0.452^{* *}$ & $(0.220)$ & 0.058 & $(0.132)$ \\
\hline Intercept & 0.001 & $(0.004)$ & $-0.007^{* *}$ & $(0.003)$ & -0.001 & $(0.002)$ \\
TD/(TC+LTD) & 0.002 & $(0.218)$ & -0.090 & $(0.172)$ & 0.118 & $(0.103)$ \\
Beta & 0.000 & & 0.004 & & 0.001 & \\
\hline $\mathrm{R}^{2}$ & 0.016 & & $2.387^{* *}$ & & 0.681 & \\
F-statistics & 1244 & & 1244 & & 1244 & \\
Observations & -0.014 & $(0.279)$ & $0.452^{* *}$ & $(0.220)$ & 0.058 & $(0.132)$ \\
\hline
\end{tabular}

Mixed relations for the US are also reflected in the distribution of quintile-returns. Apart from one and 36 months, average returns do not follow a clear pattern. For the one month holding period, higher leverage portfolios yield higher mean returns and lower leverage portfolios yield lower mean returns. However, for the 36-month period, we identify a pattern which is well 
followed in Germany and the UK markets: lower $T D /(T C+L T D)$ quintiles have higher returns than higher $T D /(T C+L T D)$ quintiles. T-tests show that for the six and 36 months period, differences between mean abnormal returns of P1 and P5 are statistically significant at the 10\%-level.

Table 11: Mean monthly abnormal returns for the US market for different periods

\begin{tabular}{|l|r|r|r|r|r|r|}
\cline { 2 - 7 } \multicolumn{1}{l|}{} & AR1 & AR3 & AR6 & AR12 & AR36 & AR60 \\
\hline P1 (lowest) & 0.197 & 0.954 & 0.487 & 0.533 & 0.583 & 0.240 \\
P2 & -1.793 & -0.373 & -0.259 & -0.229 & -0.085 & -0.104 \\
P3 & -0.096 & -0.502 & -0.238 & -0.328 & -0.179 & -0.116 \\
P4 & 0.547 & 0.047 & -0.432 & -0.069 & -0.251 & -0.031 \\
P5 (highest) & 0.663 & 0.461 & -0.144 & 0.224 & -0.061 & 0.018 \\
\hline P1-P5 & -0.467 & 0.492 & 0.631 & 0.308 & 0.644 & 0.221 \\
t-value & -0.57 & 0.95 & $1.64 *$ & 0.69 & $1.64 *$ & 0.91 \\
\hline
\end{tabular}

Cumulative average abnormal returns demonstrate that holding P1 for long periods proves profitable for the US market, too. The average cumulative abnormal return of $\mathrm{P} 1$ is 21.0 percent for 36 months and 14.4 percent for 60 months.

Table 12: Mean cumulative abnormal returns for the US market for different periods

\begin{tabular}{|l|r|r|r|r|r|r|}
\cline { 2 - 7 } \multicolumn{1}{l|}{} & CAR1 & CAR3 & CAR6 & CAR12 & CAR36 & CAR60 \\
\hline P1 (lowest) & 0.20 & 2.86 & 2.92 & 6.39 & 20.99 & 14.37 \\
P2 & -1.79 & -1.12 & -1.55 & -2.75 & -3.07 & -6.26 \\
P3 & -0.10 & -1.51 & -1.43 & -3.94 & -6.45 & -6.99 \\
P4 & 0.55 & 0.14 & -2.59 & -0.82 & -9.02 & -1.84 \\
P5 (highest) & 0.66 & 1.38 & -0.86 & 2.69 & -2.19 & 1.09 \\
\hline
\end{tabular}


Figure 3 is a summary of the performance of P1. Moreover, it shows that for the 36 month holding period, apart from P1, all the other portfolios have negative returns. In addition to the three months holding period, for all other investment horizons, P1 is the most successful quintile and P5 the second in rank. Figure 3 also shows that in comparison to the German and UK markets, P5 performs relatively well.

Figure 3: Mean cumulative abnormal returns for the US market for different periods

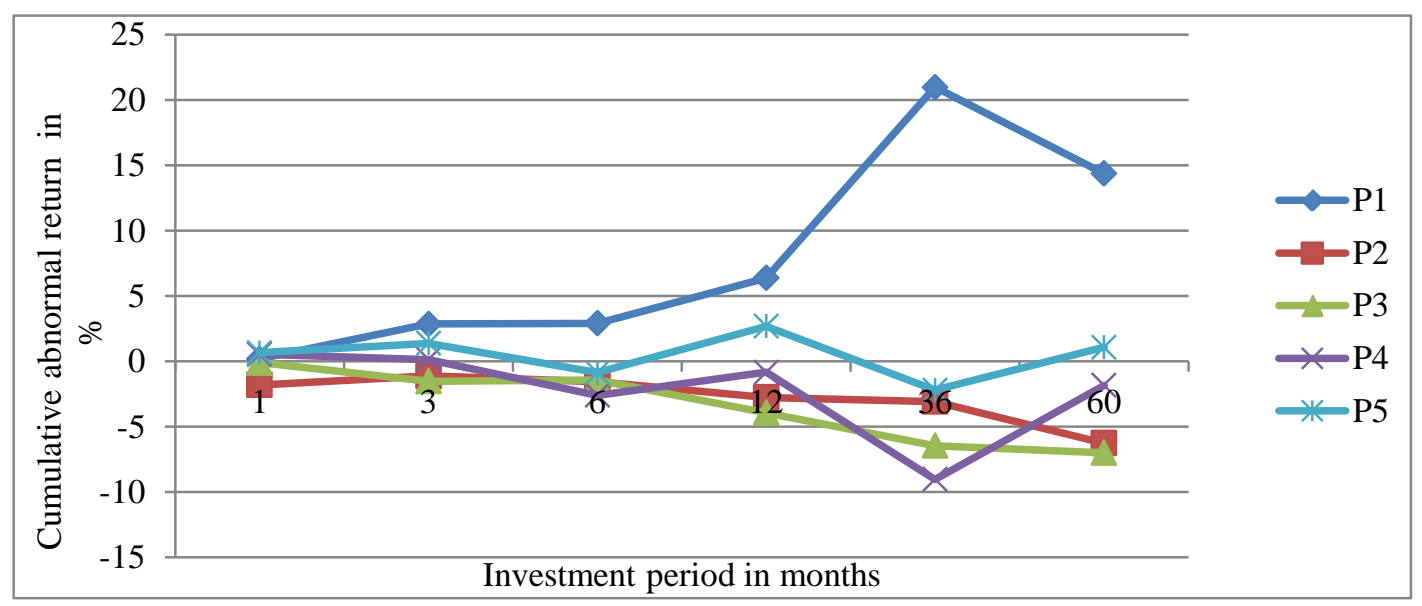

\section{Interpretation}

Regarding the inconclusive results of prior research, the negative relation between $T D /(T C+L T D)$ and stock returns which holds at least for Germany and the UK seems surprising at first sight. What might be the reasons? One possibility is that our findings for these two countries might be an anomaly: that lower $T D /(T C+L T D)$ firms indeed earn higher risk adjusted stock returns than higher $T D /(T C+L T D)$ firms. This implies that due to mispricing, low $T D /(T C+L T D)$ stocks are on average bargains and high $T D /(T C+L T D)$ stocks are pricey. In this case investors could be able to exploit mispricing by buying low $T D /(T C+L T D)$ stocks and selling (shortselling) high $T D /(T C+L T D)$ stocks. Another explanation is that the betafactor is not a suitable substitute for risk? Assuming that this is true, the following question comes to mind: does it make sense that higher returns of low $T D /(T C+L T D)$ stocks are a compensation for risk (which the betafactor does not measure)?

Before answering this question let's demonstrate what $T D /(T C+L T D)$ actually captures. If a firm has no debt, $T D /(T C+L T D)$ is zero. If debt increases, $T D /(T C+L T D)$ increases, too. However, long term debt and short term are treated differently by the ratio. Therefore, $T D /(T C+L T D)$ rises faster and obtains higher values with increasing short term debt (STD) than with increasing 
long term debt (LTD). In addition, let's focus on the relation between risk and leverage as well as between risk and debt maturity to answer the question if risk differences are a plausible explanation for our finding. Kose (2011) addresses the relation between risk and leverage in a model that accounts for debt maturity. The model predicts that risk increases with leverage. However, it also suggests that risk decreases with debt maturity: the rationale is that companies opt for their optimal maturity of debt. Companies which act in risky environments and have a relatively low credit quality have to bear particularly high issuance costs of long term debt. Therefore according to the model these firms try to avoid long term debt or choose a relatively low fraction of long term debt.

On the contrary, companies which operate in less risky environments and have higher credit quality opt for a higher fraction of long term debt. The reason is that issuance costs of long term debt are relatively low for those companies. As a result the model predicts that those firms with a high fraction of STD are riskier than firms with a high fraction of LTD. For our ratio the implication of the model is that risk should clearly increase with rising $T D /(T C+L T D)$. For one thing that is the case because of the prediction that risk increases with leverage and for another thing because of the prediction that risk decreases with debt maturity.

Investment-based theories also suggest a negative relation between risk and debt maturity. For example, Chen, Novy-Marx and Zhang (2010) suggest that companies with higher investment are less risky and have lower expected returns than companies with lower investment. The reasoning is that low cost of equity lead to higher investment. Carlson, Fisher and Giammarino (2004) also predict that investment is negatively related to risk and expected returns. It is plausible to infer that higher investment involves a higher fraction of long term debt. More importantly, Kose (2011) demonstrates that this relation also holds empirically. Accordingly, investmentbased models also suggest a positive relation between risk and $T D /(T C+L T D)$. Considering these theories, our finding [the negative relationship between $T D /(T C+L T D)$ and stock returns for markets in Germany and the United Kingdom] is even more puzzling: in our view this result cannot be explained by rational behavior of investors.

Another question that arises is: Why are results for the US market different from results for the German and UK market? Why is the relation between $T D /(T C+L T D)$ and stock returns mixed for the United States while it is negative for Germany and the United Kingdom. One possible answer is that the US market is more efficient than the other two markets. Although the German and the UK markets are not small by any measure, the US market is observed from all parts of the world and followed by many more investors than the other two. There is certainly a distinct 
difference in terms of international investor participation: for example an average diversified German investor might well hold US-stocks. In contrast, it is rather untypical for a US-American investor to hold European or even German stocks. Notice that the value of share trading at NYSE and NASDAQ is more than ten times the value of share trading at London Stock Exchange and more than 17 times the value of share trading at Deutsche Börse. In 2011, share trading at NYSE and NASDAQ was 30,751 billion USD in comparison to 2837 billion USD at London Stock Exchange and 1758 billion USD at Deutsche Börse (World Federation of Exchanges, 2012).

The difference cannot be explained by GDP differences between countries. Studies find that stock markets with higher value of share trading are more efficient than stock markets with lower value of share trading (Butler and Malaikah, 1992, or Claessens, Dasgupta and Glen, 1995). It is plausible that higher competition among investors in the US market leads to a leveling out of investment mistakes. This would imply that in contrast to respective stocks from other two markets, low leverage S\&P100-stocks get bought by rational investors before severe mispricing occurs. In the German and UK market, however, major mispricing might lead to substantial return differences between low $T D /(T C+L T D)$ - and high $T D /(T C+L T D)$-stocks.

\section{Conclusion}

This paper contributes to understanding the relation between leverage and stock returns. Contrary to other studies, we choose the ratio of 'Total Debt to (Total Capital + Long Term Debt)' $[T D /(T C+L T D)]$ and account for different maturities of debt. That is crucial because short-term debt and long-term debt are used for different purposes. We test the link between $T D /(T C+L T D)$ and equity returns for markets in Germany, the United Kingdom and the United States. Interestingly, for Germany and the United Kingdom the relation between $T D /(T C+L T D)$ and stock returns is negative and often significant; whereas for the United States the results are mixed. Our portfolio-based approach confirms this finding: low-TD/(TC+LTD) portfolios perform considerably better than high-TD/(TC+LTD) portfolios in the German and the UK markets while in the US market there is no clear pattern. Under classical models, our findings for the German and the UK markets are not explicable by traditional finance paradigm: a risk-based explanation is not plausible. Therefore, we attribute our findings to mispricing. However, one burning question arises: why do results for the USA differ from results of the other two countries? One possible explanation is that the US market is more efficient due to size and international investor participation. 
A limitation of our study is that samples are relatively small. More comprehensive samples may result in even more significant findings. Future research may conduct tests with larger samples. Furthermore, it would be interesting to perform a similar study in developing markets. According to our reasoning, a negative link between $T D /(T C+L T D)$ and stock returns would not be surprising due to lower efficiency of those markets.

Authors Information: Tristan Nguyen, WHL Graduate School of Business and Economics, Landsberger Str. 257 b, 80687 Munich, Germany. Tel: +49(0)7821-923865. E-mail: tristan.nguyen@whl-lahr.de. Alexander Schüßler, HHL Leipzig Graduate School of Management, Oetztalerstrasse 12, 81373 Munich, Germany. Tel: +49(0)173-9521060. E-mail: alexander.schuessler@hhl.de

\section{References}

Arditti, F. D., (1967). Risk and return on equity. Journal of Finance, 22 (1): 19-36.

Bhandari, L. C., (1988). Debt/equity ratio and expected common stock returns: empirical evidence. Journal of Finance, 43: 507-528.

Butler, K. C., and Malaikah, S. J., (1992). Efficiency and inefficiency in thinly traded stock markets: Kuwait and Saudi Arabia. Journal of Banking and Finance, 16 (2): 197-210.

Campbell J. Y., Lo A. W., and MacKinlay A. C., (1997). The Econometrics of Financial Markets ( $1^{\text {st }}$ ed.). Princeton: Princeton University Press: 149-178.

Carlson, M., Fisher, A., and Giammarino, R., (2004). Corporate investment and asset price dynamics: implications for the cross-section of returns. Journal of Finance, 59: 2577-2603.

Caskey, J., Hughes, J. S., and Liu, J., (2012). Leverage, excess leverage and future returns. Review of Accounting Studies, 17: 443-471.

Chen, L., Novy-Marx, R., and Zhang, L., (2010). An alternative three-factor model. Working paper. Available at SSRN: http://dx.doi.org/10.2139/ssrn.1418117.

Claessens, S., Dasgupta, S., and Glen, J., (1995). Return behavior in emerging stock markets. The World Bank Economic Review, 9 (1): 131-51.

DeBondt, W., and Thaler, R., (1987). Further evidence on investor overreaction and stock market seasonality. Journal of Finance, 42: 557-581.

Dhaliwal, D. S., Heitzman, S., and Zhen L. O., (2006). Taxes, leverage, and the cost of equity capital. Journal of Accounting Research, 44 (4): 691-723.

George T., and Hwang C., (2009). Leverage, financial distress and the cross section of stock returns. Journal of Financial Economics, 96 (1): 56-79.

Gombola, M. J., and Liu, F. J., (1993). Dividend yields and stock returns: evidence of time variation between bull and bear markets. Financial Review, 28: 175-192.

Graham, J. R., and Harvey, C. R., (2001). The theory and practice of corporate finance: evidence from the field. Journal of Financial Economics, 60: 187-243.

Grinblatt, M., and Han, B., (2004). Prospect theory, mental accounting, and momentum. Journal of Financial Economics, 78 (2): 311-339. 
Keppler, A. M., (1991). The importance of dividend yields in country selection. Journal of Portfolio Management, 17: 24-29.

Korteweg, A., (2004). Financial leverage and expected stock returns: evidence from pure exchange offers. Working paper. Available at SSRN: http://dx.doi.org/10.2139/ssrn.597922

Kose, E., (2011). Dissecting the leverage effect on stock returns. Working paper. Available at:http://www.business.uconn.edu/finance/seminars/papers/Dissecting\%20the\%20Leverage \%20Effect\%20on\%20Stock\%20Returns.pdf

Miller, M., (1977). Debt and taxes. Journal of Finance, 32: 261-275.

Modigliani, F., and Miller, M., (1958), The cost of capital, corporation finance, and the theory of investment. American Economic Review, 48 (3): 261-297.

Modigliani, F., and Miller, M., (1963). Corporate income taxes and the cost of capital: a

correction. American Economic Review, 53: 433-443.

Muradoglu, Y., and Sivaprasad, S., (2012a). Using firm level leverage as an investment strategy. Journal of Forecasting, 31: 260-279.

Muradoglu, Y., and Sivaprasad, S., (2012b). Capital structure and abnormal returns. International Business Review, 21: 328-341.

Patel, P., Yao, S., and Barefoot, H., (2006). High yield, low payout, Credit Suisse Quantitative Equity Research.

Penman, S. H., Richardson, S. A., and Tuna, I., (2007). The book-to-price effect in stock returns: accounting for leverage. Journal of Accounting Research, 45 (2): 427-467.

World Federation of Exchanges (2012). 2011 WFE market highlights, retrieved June 14, 2012 from http://www.world-exchanges.org/files/file/stats\%20and\%20charts/2011\% 20WFE\%20Market\%20Highlights.pdf 